Scientific Review - Engineering and Environmental Sciences (2018), 27 (4), 504-515

Sci. Rev. Eng. Env. Sci. (2018), 27 (4)

Przegląd Naukowy - Inżynieria i Kształtowanie Środowiska (2018), 27 (4), 504-515

Prz. Nauk. Inż. Kszt. Środ. (2018), 27 (4)

http://iks.pn.sggw.pl

DOI 10.22630/PNIKS.2018.27.4.47

Ivan KERNYTSKYY ${ }^{1}$, Bohdan DIVEYEV ${ }^{2}$, Ihor STUKALETS ${ }^{3}$, Orest HORBAY ${ }^{2}$, Serhii BEREZOVETSKYI ${ }^{3}$, Serhii BARANOVYCH ${ }^{3}$

${ }^{1}$ Faculty of Civil and Environmental Engineering, Warsaw University of Life Sciences SGGW

${ }^{2}$ Institute of Mechanical Engineering and Transport, Lviv Polytechnic National University

${ }^{3}$ Faculty of Mechanic and Energetic, Lviv National Agrarian University

\title{
Vibration absorber optimization for boom-sprayer
}

Key words: boom-sprayer, vibroprotection, design, vibration absorber, suspension, optimization

\section{Introduction}

Uniform spray deposits by boomsprayers onto surface surrounding the sprayed field has gained much attention. Reduction of the amount of chemicals used as well as reduction of spray drift may be achieved by improved and new application techniques. The discrete-continue models of machines dynamics of such wheeled machines as boomsprayer with elongated boom element are offered. The algorithms for vibration decreasing of boom are received. The new vibroabsorbing elements are proposed.

Optimal design of agricultural units, including boom sprayers, covers a wide range of engineering disciplines - from technical to environmental. In this paper, based on the previously known and obtained mathematical models of dynamics and durability of complex structures, the problem of multicriterial rational design of the boom sprayers is solved.

The question of stabilization in the vertical and horizontal plane of the main element of the constructions of the aggregate - a large-sized rod in the modes of dynamic loading when moving the sprayer on the relief of the field is considered. At insufficient level of stabilization of a rod in a vertical plane it is possible to contact the rod with the surface of the field. This is facilitated by the fact that, often under technological conditions, the height of the rod does not exceed $0.5 \mathrm{~m}$ above the field level. Thus, along with uneven spraying, insufficient stabilization of the rod can cause its breakage. The oscillation of the bar, especially in the horizontal direction, greatly affects the uniformity of the spraying. The horizontal plane of oscillation often acts as 
the most dangerous to the strength, since the most common construction of the rod - a flat vertical farm.

The known numerous methods of modelling and complex optimization of the boom-sprayer and spray drift belong to authors (Sinfort et. al., 1997; De Jong, Van de Zande \& Stallinga, 2000; Herbst \& Wolf, 2000; Ooms, Lebeau, Ruter \& Destain, 2002). We will note that application only these programs are often insufficient. At first, the dynamics loadings, which act on a frame under the real exploitation conditions, are not exactly known, and the use for this purpose a model "suspension-rigid body" is scarcely correctly. The real effective optimization of multi-element model is not really. The algorithms of condensation a model are here usually used to a little size model on which it is possible to make optimization (Kernytskyy, Diveyev, Vybranets \& Kernytskyy, 2008; Diveyev, Vikovych, Dorosh \& Kernytskyy, 2012; Sava, Kernytskyy \& Diveyev, 2013; Diveyev, Beshley, Konyk \& Kernytskyy, 2015a; Diveyev, Kernytskyy, Kopytko, Konyk \& Kogut, 2015b; Diveyev, Horbay, Kernytskyy, Pelekh \& Velhan, 2017; Kernytskyy et., 2017). The large number of articles on this subject during several decades shows that clear quantitative results are very hard to obtain. Inevitable variation of too many parameters at the same time may obscure an unambiguous interpretation of those results. Using computer simulation to investigate spray drift may help to clarify some of the problems, since all parameters can be changed freely. Models to simulate drift can be divided roughly into plume models and random-walk models.
However, it still is difficult to describe short-range drift by plume models, mainly because of the problems to account for near-nozzle features of the spray cloud (including mathematical singularity at the nozzle outlet) as well as sedimentation of evaporating droplets. Undesired spray boom movements together with pressure variations in the hydraulic equipment, badly worn nozzles, spray displacement due to gusts of wind and variations in the forward speed of the tractor can all adversely affect spray distribution. Unwanted boom movements including rolling, vertical movements and yawing of the spray boom, are caused by tractor vibrations, mainly induced by unevenness of the soil. Adverse effects due to tractor rolling on the spray pattern have been investigated extensively and numerous boom suspension systems to attenuate this are applied in practice. Vertical flexible deformations of the boom, induced by rolling angular and vertical accelerations of the tractor, are largely neutralized by the frame structure of the boom and thus have less impact on the spray distribution. Transversal accelerations and yawing angular accelerations of the tractor create horizontal flexible deformations of the spray boom. Field measurements and simulations with experimental modal models of different spray booms have demonstrated that horizontal boom vibrations, especially flexible deformations and to a lesser degree rigid body yawing, are responsible for localized under and over applications. These can vary between 20 and $600 \%(100 \%$ is the ideal or nominal distribution which will be obtained without boom vibrations) and are of the same order as the impact of tractor rolling. 
Each time the absolute velocity of the nozzles passes back through standstill or becomes negative by backward bouncing of the boom, the pattern is distinctly changed. Even small boom vibrations (less than $30 \mathrm{~cm}$ ) which occur frequently in field operations, can cause overlap of spray distributions. A simple calculation confirms this statement. Flexible boom deformations are almost entirely determined by the flexible mode corresponding to the fundamental (or lowest) frequency of the boom (vibration of the boom in its fundamental mode is also called bouncing).

The paper contemplates the provision of dynamic vibration absorbers (DVA) or any number of such absorbers (Timoshenko, 1955; Snowdon, 1968; Inman, 1996). Such originally designed absorbers reduce vibration selectively in maximum vibration mode without introducing vibration in other modes. For example, the final result is achieved by DVA at far less expense compared to the cost needed to replace the concrete and steel foundation with a new, sufficiently massive one. In order to determine the optimal parameters of an absorber the need for complete modeling of rotating machine dynamics is obvious. Present research has developed a modern prediction and control methodology, based on a complex continuum theory and the application of special frequency characteristics of structures.

The problem of attaching DVA to a discrete multi-degree-of-freedom or continuous structure has been outlined in many papers (Bishop \& Welbourn, 1952; Warburton, 1957; Hunt, 1979; Snowdon, 1968; Korenev \& Reznikov, 1993; Aida, Aso, Nakamoto \& Kawazoe, 1998;
Marhadi \& Kinra, 2005; Saeki, 2005; Shah et al., 2009). To calculate and optimize the beam with the DVA, the beam is usually considered as a continuumbased element based on the theory of the Bernoulli-Euler or Timoshenko beam. DVA is considered as a discrete system, ideally connected to the beam.

In Jacquot (1978) the general system involving a Bernoulli-Euler beam are considered. For beam modeling, the classical Fourier method is used. In calculations, only the first mode of oscillation is used. This is quite logical, since the low-frequency range is considered, where this form dominates. In Nagaya, Kurusu, Ikai and Shitani (1999) the vibration response was obtained by using the transfer matrix method and FEM for beam. But here only linear equations in the frequency domain are considered. Nonlinear phenomena both in the dynamics of the beam and in the DVA are a priori excluded. Even in this article, in the experimental vibrograms given above, we see significant nonlinear phenomena that do not correlate with the theory of the article.

In Nagaya et al. (1999) the partial differential equations governing the beam dynamics have been reduced to a set of ordinary differential equations (ODEs) by means of the Galerkin-Bubnov approach, which leads to a linear or nonlinear system of ODEs, depending on the type of damper connected to the beam. Eigen functions of the beam problem without dampers are considered in the displacement expansion. Here again the system of equations and results is rather opaque. Although moving loading and stochastic phenomena are also considered, the results are not systematized, 
but in some ways obscure. There is no comparison of linear and nonlinear DVA (with artificial cubic nonlinearity). In Wong, Tang, Cheung and Cheng (2007) finite element analysis Bernouli-Euler beam theory are used for evaluation of the performance of vibration isolation of the proposed absorber mounted on a beam. Though in Wong et al. (2007) a linear and twisting DVA are considered, there is no comparison of results, neither theoretic nor experimental.

In Saffury and Altus (2010) on the basis of a rather cumbersome asymptotic model, only a frequency band is considered for a two-stage Euler beam. It may be noted that these works are too complex theoretically, they do not have either real load or real DVA (for example roller type).

Although some parameters of DVA can be determined by experiments, but some, such as basic system mass $m_{1}$ remains unknown. For a more precise definition of the model parameters several additional experiments must be conducted (for the definition of the primary system parameters). At the same time DVA parameters require refinement. Although they can be calculated more accurately than the basic parameters of the system, yet it takes a lot of effort both in determining of the elastic properties of DVA and DVA clamping plate. The numerical schemes (NS) row for the complex vibro-loaded construction and methods of decomposition and the NS synthesis are considered in our paper on the basis of new methods of modal synthesis (Kernytskyy et al., 2008, 2017; Diveyev et al., 2012, 2015a, b; Sava et al., 2013).

\section{Dynamic characteristics of the boom}

In Figure 1 the boom-sprayer with DVA's is presented. The bar of the boomsprayer is usually flat for a size bar less than $18 \mathrm{~m}$ or a spacious farm for a larger rod. There are bars and box-shaped sections. The sprayer has three load cycles: (1) the transport position; (2) deployment; (3) working position. We will consider the working position of the rod. The rod, as well as the overwhelming number of machine elements, should

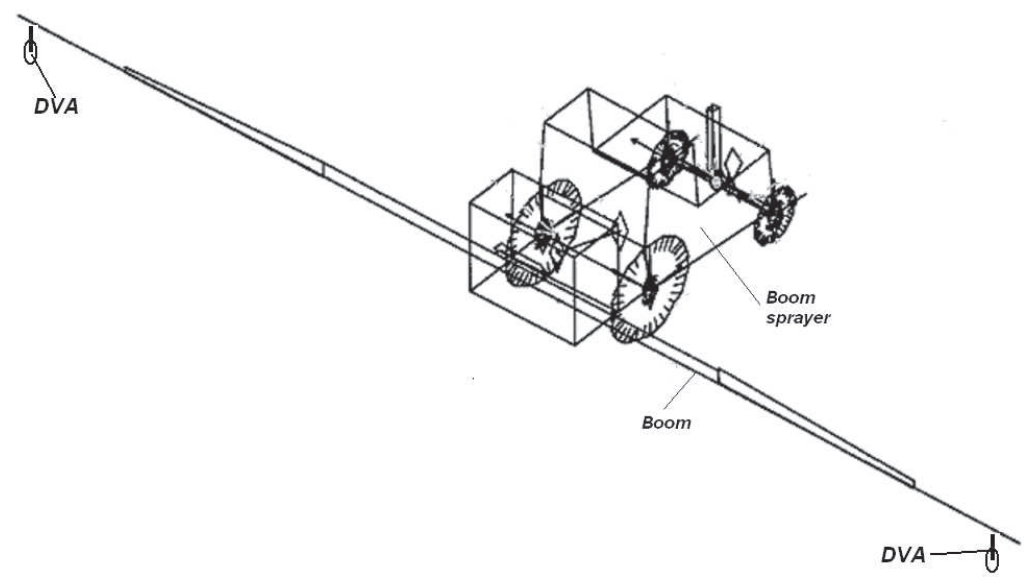

FIGURE 1. Boom-sprayer with DVAs 
be considered in cyclic loads. The main source of dynamic perturbations of the rod sprayer, as well as for each wheeled unit, is the interaction of the wheels with the relief of the field. The character of the amplitude-frequency characteristics are shown in Figure 2.

They are obtained for various speeds $\left(4,8,12 \mathrm{~km} \cdot \mathrm{h}^{-1}\right)$ of the unit on the basis of experimental studies (Herbst \& Wolf al., 2000). As can be seen, the frequency characteristics of external perturbations are concentrated in the low-frequency range.

Now determine the frequency characteristics of the boom. The first resonance frequency is $1.8 \mathrm{~Hz}$. Now define the static stiffness at the point indicated by the arrow (Fig. 3). In the $z$ direction (perpendicular to the farm's plane) we set the force to $1,000 \mathrm{~N}$ and determine the displacement. Let's give the first form of the vibrations of the farm (Fig. 3).
These data will take us long to construct a mathematical model of the boom wing and determine its parameters.

\section{The basic equation for identification}

Taking into account that both the first resonance frequency of the rod wings and the peak of external perturbation are in the low-frequency range, consider the 1-mass model (single degree of freedom - SDOF) of the rod wings (Fig. 4).

This mass is on a weightless beam (a), equivalent to the classical 1-mass model - the weight on the spring (b). The numerical model is described by the following differential equation:

$m \ddot{w}+k D \dot{w}+k w=F$

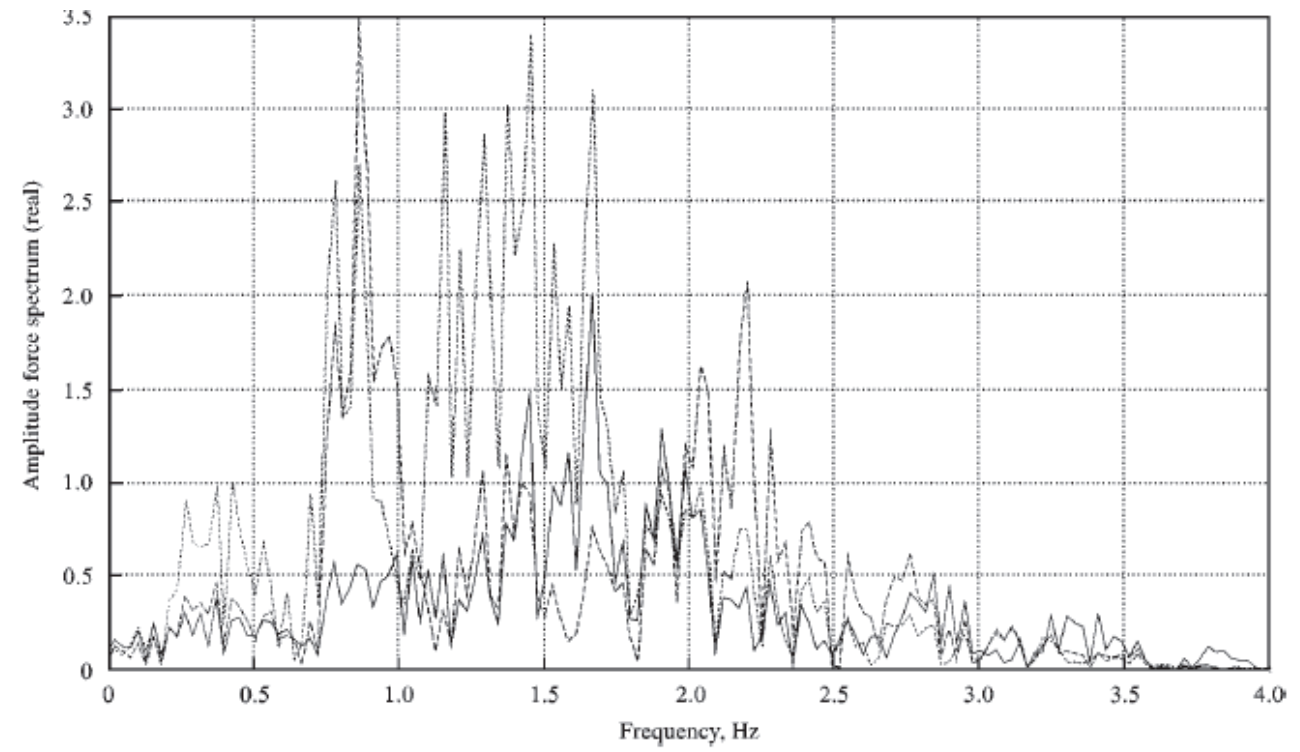

FIGURE 2. Frequency characteristics of external perturbation for rod sprayer (input intensities at $4 \mathrm{~km} \cdot \mathrm{h}^{-1}$ - solid line; $8 \mathrm{~km} \cdot \mathrm{h}^{-1}$ - dotted line; $12 \mathrm{~km} \cdot \mathrm{h}^{-1}$ - point line) (Wong et al., 2007) 


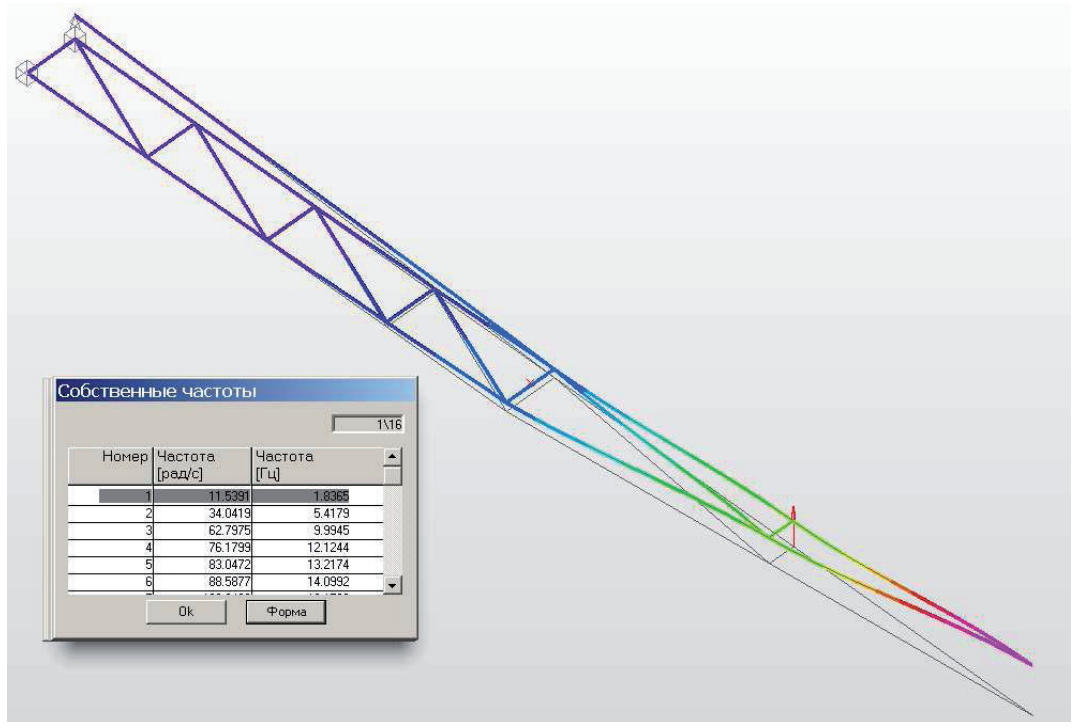

FIGURE 3. The first form of fluctuations of the boom wing

a

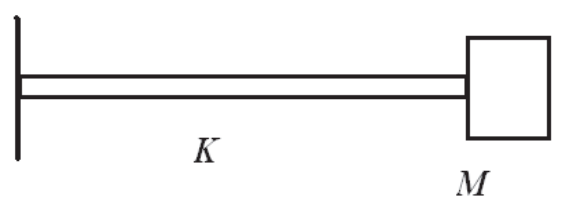

b

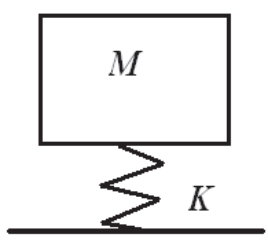

FIGURE 4. One-mass model of the boom

were:

$k$ - appropriate stiffness;

$D$ - coefficient of viscous damping;

$w$ - displacement;

$F$ - perturbation. Parameters $m, k, D$ are unknown. Define $m, k$ based on the resonance frequency and rigidity found above. Rigidity $k$ is determined on the basis of Figure 3.

$k=F / \Delta \approx 1,000 / 0.295 \approx 4,556 \mathrm{~N} \cdot \mathrm{m}^{-1}$

The mass is now determined on the basis of the formula $m=k / \omega^{2} \approx 4,556 / 11.54^{2} \approx 34.2 \mathrm{~kg}$

The weight in the model is three times smaller than the weight of the rod wing.

\section{Condensed model of the beam - DVA}

Let us consider condensed model of impact masses DVA - primary system. The impact mass type DVA is presented: an additional impact mass in container 
with elastic barrier elements. Consider now the DVA with 3 different impact masses in one container (Fig. 5).

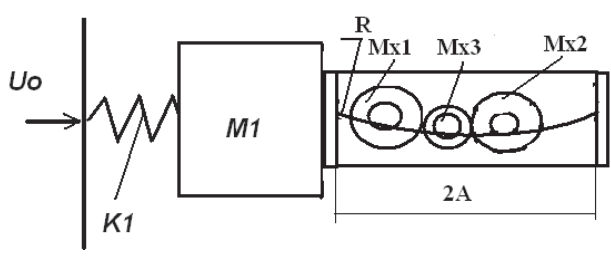

FIGURE 5. DVA with 3 different impact masses in one container

The system of equations is now
The nonlinear functions $F_{13}\left(u_{X 1}, u_{X 3}\right), F_{23}\left(u_{X 2}, u_{X 3}\right)$ of DVA's masses interaction may be defined analogously

$$
\begin{aligned}
& F_{13}=F_{13}\left(x_{1}-x_{3}\right) \quad\left|x_{1}-x_{3}\right|<R_{1}+R_{3} \\
& F_{13}=0 \quad\left|x_{1}-x_{3}\right|>R_{1}+R_{3}
\end{aligned}
$$

$$
\begin{aligned}
& m_{1} \frac{d^{2} u_{1}}{d t^{2}}+k_{1}\left(u_{1}-u_{0}\right)+k_{A}\left(u_{1}-u_{A}\right)-m_{X 1} / R_{X 1}\left(u_{X 1}-u_{A}\right)+k_{X 1} F_{1}\left(u_{1}-u_{X 1}\right)- \\
& -\ldots-m_{X N} / R_{X N}\left(u_{X N}-u_{A}\right)+k_{X N} F_{N}\left(u_{1}-u_{X N}\right)=F(t)
\end{aligned}
$$

$m_{X 1} \frac{d^{2} u_{X 1}}{d t^{2}}+m_{X 1} / R_{X 1}\left(u_{X 1}-u_{A}\right)-k_{X 1} F_{1}\left(u_{1}-u_{X 1}\right)+F_{12}\left(u_{X 1}, u_{X 2}\right)+F_{13}\left(u_{X 1}, u_{X 3}\right)=0$

$m_{X 2} \frac{d^{2} u_{X 2}}{d t^{2}}+m_{X 2} / R_{X}\left(u_{X N}-u_{A}\right)-k_{X} F_{N}\left(u_{1}-u_{X 2}\right)-F_{12}\left(u_{X 1}, u_{X 2}\right)+F_{23}\left(u_{X 2}, u_{X 3}\right)=0$

$m_{X 3} \frac{d^{2} u_{X 3}}{d t^{2}}+m_{X 2} / R_{X}\left(u_{X N}-u_{A}\right)-F_{13}\left(u_{X 1}, u_{X 3}\right)-F_{23}\left(u_{X 2}, u_{X 3}\right)=0$

Here three DVA's masses are considered. Parameters $m_{1}, k_{1}$ of the prime system may be found by means of FEM or experimentally. The nonlinear functions are

$F_{i}=-K_{v i}\left(x_{i}-A_{i}\right) \quad\left|x_{x}\right|>A_{i}$

$F_{i}=0 \quad\left|x_{i}\right|<A_{i}$

$F(t)=a \sin (\omega t)$

were:

$A$ - clearance;

$K_{v i}$ - boundary elements rigidity.
Let us consider the optimization of this DVA's by criterion

$C i L=\max \left[x_{1}(t)\right], t>t_{P}$

Coordinates $x_{1}, x_{2}, x_{3}$ of the impact masses and the differences between this coordinates $x_{1}, x_{3}$ and $x_{2}, x_{3}$ are presented in Figure 6.

The results of DVA's application is shown in Figure 7.

The 3-mass impacts DVA seems to be better then independent 3 DVAs with 
a

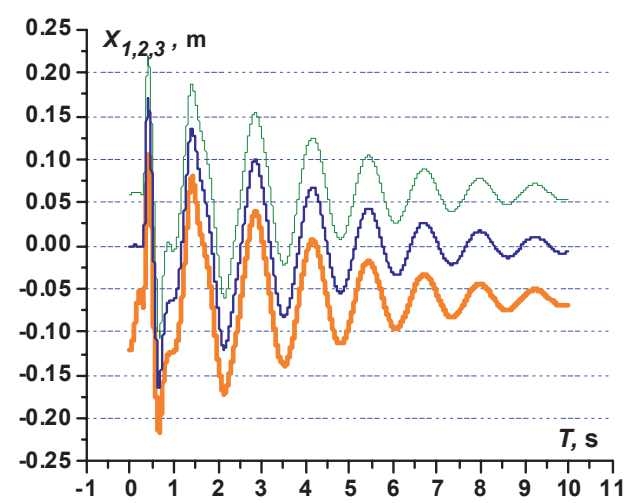

b

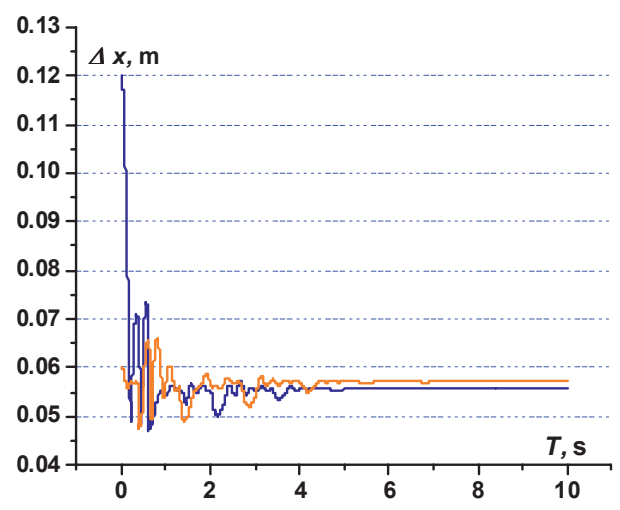

FIGURE 6. Coordinates $x_{1}, x_{2}, x_{3}$ of the impact masses (a); the differences between this coordinates $x_{1}$, $x_{3}$ and $x_{2}, x_{3}(\mathrm{~b})$

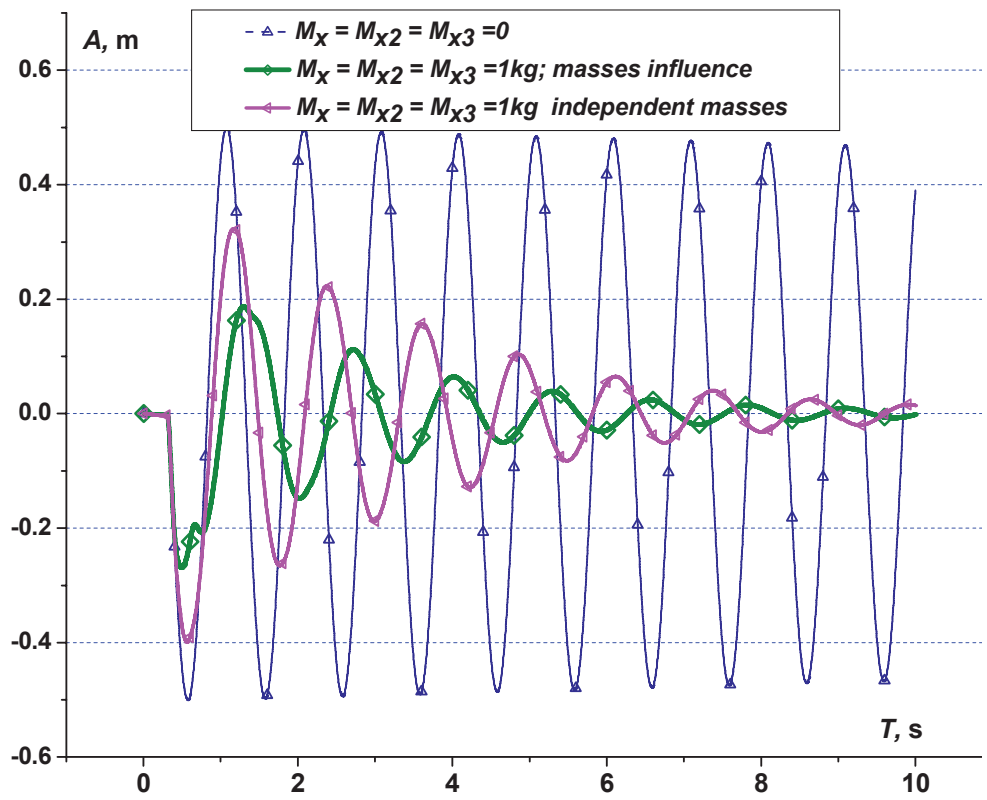

FIGURE 7. Results of DVA's application

the same masses. Here the optimization in the real time is done.

Present research develops the genetic algorithms for optimization searching by discrete-continuum DVA's system - base system modeling (Kernytskyy et al.,
2008, 2017; Diveyev et al., 2012; Sava et al., 2013).

Here 8 parameters of optimization are used: fx, fx2 DVA's eigenfrequencies; $\mathrm{Dx}, \mathrm{DG}$ - proportional viscous damping in container and in barrier (added to all 


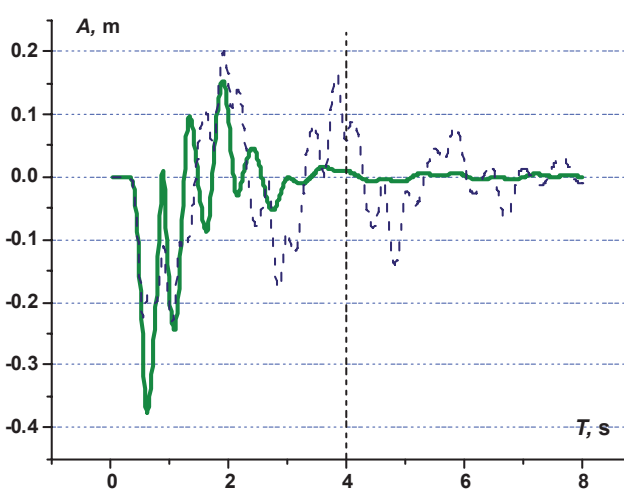

FIGURE 8. Results of 1-mass DVA (dash line) and 3-mass DVA optimization
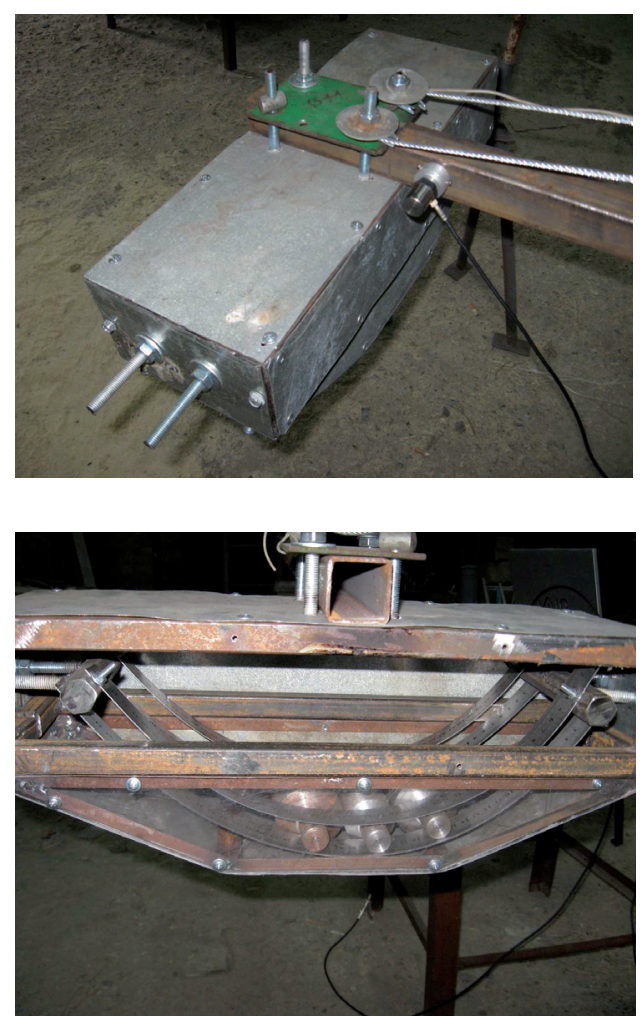

FIGURE 9. The experimental example of DVA (in natural size) equations terms $\left.k_{X i} D_{X i} \mathrm{~d} u_{i} / \mathrm{d} t\right), M x 3-$ less DVA' mass, $f K K$ - DVA's masses inter-collision and $f K x$ - DVA's masses on barrier collision Eigen frequencies. Ax is clearance half length. The prime system mass is $m_{1}=10 \mathrm{~kg}$, the prime system Eigen frequency $-f_{R}=1 \mathrm{~Hz}=6.28 \mathrm{rad} \cdot \mathrm{s}^{-1}$, the proportional damping $-D 1=0.03$.

In Figure 8 results of 1-mass DVA and 3-mass DVA optimization are presented.

The 1-mass DVA is worse than 3-mass. The upper results are achieved with the Boltzman approximation for contact forces (Diveyev et al., 2012; Sava et al., 2013). In Figure 9 the experimental example of this DVA (in natural size) is shown.

Experimental results are as in Figure 8 . This was achieved by the DVA frequency regulation and high damping as result of dry friction in the masses contacts.

\section{Discussion}

In the field, the horizontal movements largely influence the spray deposit longitudinal distribution, even if other parameters such as boom height variations and wind effect are present. On the basis of research of mechanical processes, these models are realized in a number of program complexes. On their basis the algorithms for spray deposit definition of boom-sprayer are obtained. We will note that the mathematical models, numerical algorithms and programmatic facilities developed for this class of vehicles are adapted and for other vehicles. A sprayer equipped with a horizontal suspension should thereto be a good choice for re- 
ducing spray coverage variations in the longitudinal direction. The additional cost of such a device should be compared to the savings made by reducing the spray coverage variations. The suspension efficiency, the product costs and the ecological benefits are the other parameters to take into account.

\section{Conclusions}

The discrete-continue models of wheeled land-machines and processes related to their functioning are offered. On the basis of research of mechanical processes, these models are realized in a number of program complexes. On their basis the algorithms for optimum planning of boom-sprayer suspension are obtained. In order to determine the optimal parameters of DVA for the boom vibration in horizontal direction the complete modeling of dynamics of devices should be made. Paper deals with the new methods for the explicit determination of the frequency characteristics of DVA by narrow frequency excitation. Few parameters numerical schemes of vibration analysis are under discussion. The influence of elastic and damping properties of the basic construction and dynamic vibration absorbers are considered. The discrete-continue models of machines dynamics of elongated elements or such machines as the elongated element - boom of the sprayer with the attachment of dynamic vibration absorbers are offered. The algorithms for vibration decreasing are received. The new vibroabsorbing elements are proposed. The first eigen-frequencies are calculated and obtained experimentally for different mass- es attached to elastic elements of the dynamic vibration absorbers. The one-digit values are established not only for the dynamic vibration absorber parameters, but also for mechanical parameter of base structure - pump in connection points of the dynamic vibration absorbers. Finally, present research develops the genetic algorithms for optimal design searching by discrete-continuum models of boom suspension and DVA's system - base system modeling. Uniform spray deposits by boom-sprayers onto surface surrounding the sprayed field by this innovations was got.

\section{References}

Aida, T., Aso, T., Nakamoto, K. \& Kawazoe, K. (1998). Vibration control of shallow shell structures using shell-type dynamic vibration absorber. Journal of Sound and Vibration, 218, 245-267.

Bishop, R.E.D. \& Welbourn, D.B. (1952). The problem of the dynamic vibration absorber. Engineering, 174, 796.

De Jong, A., Van de Zande, J.C. \& Stallinga, H. (2000). The effects of vertical and horizontal boom movements on the uniformity of spray distribution. Agricultural Engineering Conference Paper, 00-PM-015, 1-9.

Diveyev, B., Beshley, A., Konyk, S. \& Kernytskyy, I. (2015a). Identification of Transverse Elastic Module of Composite Beams by Using Combined Criteria. In M.J. Crocker, F. Pedrielli, S. Luzzi, M. Pawelczyk \& E. Carletti (eds.), 22nd International Congress on Sound and Vibration 2015 (ICSV 22) Volume 2/8 (pages 3998-4005). Florence: International Institute of Acoustics \& Vibration. Retrieved from: http://toc.proceedings. com/27211webtoc.pdf.

Diveyev, B., Horbay, O., Kernytskyy, I., Pelekh, R. \& Velhan, I. (2017). Dynamic Properties and Damping Predictions for Laminated MicroBeams by Different Boundary Conditions. In 2017 XIIIth International Conference on 
Perspective Technologies and Methods in MEMS Design (MEMSTECH 2017) (pages 30-34). Piscataway, NJ: Institute of Electrical and Electronics Engineers. Retrieved from: http://toc.proceedings.com/34656webtoc. pdf.

Diveyev, B., Kernytskyy, I., Kopytko, M., Konyk S. \& Kogut, V. (2015b). Sound transmission of sandwich beams with the dynamic vibration absorbers. Scientific Review Engineering and Environmental Sciences, 68, 120-132.

Diveyev, B., Vikovych, I., Dorosh, I., \& Kernytskyy, I. (2012). Different type vibration absorbers design for beam-like structures. In 19th International Congress on Sound and Vibration 2012 (ICSV 19). Volume 1/4. (pages 1499-1506). Auburn, AL: International Institute of Acoustics \& Vibration. Retrieved from: http://toc.proceedings. com/16317webtoc.pdf.

Herbst, A. \& Wolf, P. (2000). Spray deposit distribution from agricultural boom sprayers in dynamic conditions. In P. Sas \& B. Bergen (eds.), International Conference on Noise and Vibration Engineering 2010 (ISMA 2010). Volume 1/7. (pages 1599-1605). Leuven, Belgium: Katholieke Universiteit Leuven Department of Mechanical Engineering. Retrieved from: http://toc.proceedings. com/10610webtoc.pdf.

Hunt, J.B. (1979). Dynamic Vibration Absorbers. London: Mechanical Engineering Publications.

Inman, D.J. (1996). Engineering Vibration. Upper Saddle River, NJ: Prentice Hall International.

Jacquot, R.G. (1978). Optimal dynamic vibration absorbers for general beam systems. Journal of Sound and Vibration, 60(4), 535-542.

Kernytskyy, I., Diveyev, B., Vybranets, J.J. \& Kernytskyy, N. (2008). Using of dynamic vibration absorbers for regulation of vibrating compactor vibration properties. Acta Scientiarum Polonorum Architectura (Budownictwo), 7(3), 43-50.

Kernytskyy, I., Diveyev, B., Horbaj, O., Hlobchak, M., Kopytko, M. \& Zachek, O. (2017). Optimization of the Impact Multi-Mass Vibration Absorbers. Scientific Review. Engineering and Environmental Sciences, 77, 394-400.
Korenev, B.G. \& Reznikov, L.M. (1993). Dynamic Vibration Absorbers: Theory and Technical Applications. Chichester, Wiley.

Nagaya, K., Kurusu, A., Ikai, S. \& Shitani, Y. (1999). Vibration control of a structure by using a tunable absorber and an optimal vibration absorber under auto-tuning control. Journal of Sound and Vibration, 228(4), 773-792.

Marhadi, K.S. \& Kinra, V.K. (2005). Particle impact damping: effect of mass ratio, material, and shape. Journal of Sound and Vibration, 283(1-2), 433-448.

Ooms, D., Lebeau, F., Ruter, R. \& Destain, M.F. (2002). Measurements of the horizontal sprayer boom movements by sensor data fusion. Computers and Electronics in Agriculture, 33, 139-162.

Saeki, M. (2005). Analytical study of multi-particle damping. Journal of Sound and Vibration, 281, 1133-1144.

Saffury, J. \& Altus, E. (2010). Chatter resistance of non-uniform turning bars with attached dynamic absorbers-Analytical approach. Journal of Sound and Vibration, 329, 2029$-2043$.

Sava, R., Kernytskyy, I. \& Divejev, B. (2013). Optimization Of Dynamic Vibration Multi-Absorber. In K. Lejda (eds.), Systemy $i$ środki transportu samochodowego. Wybrane zagadnienia. Monografia 4. Seria: Transport. (pages 173-180). Rzeszów: Politechnika Rzeszowska.

Shah, B.M., Pillet, D., Bai, X.M., Keer, L.M., Wang, Q.J. \& Snurr, R.Q. (2009). Construction and characterization of a particle-based thrust damping system. Journal of Sound and Vibration, 326(3-5), 489-502.

Sinfort, C., Lardoux, Y., Miralles, A., Enf, P., Alness, K. \& Andersson, S. (1997). Comparison between measurements and predictions of spray pattern from a moving boom sprayer. Aspects of Applied Biology, 48, 1-8

Snowdon, J.C. (1968). Vibration and Shock in Damped Mechanical Systems. New York: Wiley.

Timoshenko, S. (1955). Vibration Problems in Engineering. New York: Van Nostrand.

Warburton, G.B. (1957). On the theory of the acceleration damper. Journal of Applied Mechanics, 24, 322-324. 
Wong, W.O., Tang, S.L., Cheung, Y.L. \& Cheng, L. (2007). Design of a dynamic vibration absorber for vibration isolation of beams under point or distributed loading. Journal of Sound and Vibration, 301, 898-908.

\section{Summary}

Vibration absorber optimization for boom-sprayer. The main task of this work is to analyze optimal design-system of the booms of boom-sprayers. The discrete-continue models of machines dynamics of such wheeled machines as boom-sprayer with elongated boom element with the attachment of dynamic vibration absorbers are offered. The algorithms for vibration decreasing of boom are received. The new vibroabsorbing elements are proposed.

The paper contemplates the provision of dynamic vibration absorbers (DVA) of buffered impact masses and particle type. Such originally designed absorbers reduce vibration selectively in maximum vibration mode, without introducing vibration in other modes. The damping results from the exchange of momentum during impacts among the masses and masses and stops as the structure vibrates. A technique is developed to give the optimal DVA's as single degree of freedom (SDOF) buffered system. The one-digit values are established not only for the dynamic vibration absorber parameters, but also for mechanical parameter of base structure - boom in connection points of the dynamic vibration absorbers. Finally, present research develops the genetic algorithms for optimal design searching by discrete-continuum DVA's system - base system modeling.

\section{Authors' address:}

Ivan Kernytskyy

Szkoła Główna Gospodarstwa Wiejskiego

w Warszawie

Wydział Budownictwa i Inżynierii Środowiska

Katedra Inżynierii Budowlanej

ul. Nowoursynowska 159, 02-776 Warszawa

Poland

e-mail: ivankernytskyy@ukr.net 